\title{
Effects of basic endoscopic handling and care training on gastrointestinal endoscopy logistics
}

\section{(ㄷ)(1) $\odot$}

\author{
Authors \\ Prasit Mahawongkajit, Ajjana Techagumpuch, Kharikarn Auksornchat
}

Institution

Department of Surgery, Faculty of Medicine, Thammasat University, Pathumthani, Thailand

submitted 27.5.2021

accepted after revision 24.8 .2021

Bibliography

Endosc Int Open 2022; 10: E56-E61

DOI 10.1055/a-1630-6403

ISSN 2364-3722

(C) 2022. The Author(s).

This is an open access article published by Thieme under the terms of the Creative Commons Attribution-NonDerivative-NonCommercial License, permitting copying and reproduction so long as the original work is given appropriate credit. Contents may not be used for commercial purposes, or adapted, remixed, transformed or built upon. (https://creativecommons.org/licenses/by-nc-nd/4.0/)

Georg Thieme Verlag KG, Rüdigerstraße 14,

70469 Stuttgart, Germany

\section{Corresponding author}

Prasit Mahawongkajit, MD, PhD, Department of Surgery, Faculty of Medicine, Thammasat University (Rangsit Campus), 95/209 Moo 18, Paholyothin Road, Amphur Klongluang, Pathumthani, 12120, Thailand

Fax: + 6629269530

prasit_md@yahoo.com

Supplementary material is available under https://doi.org/10.1055/a-1630-6403

\section{ABSTRACT}

Background and study aims The current practice of endoscopists is undergoing a dramatic revolution due to emerging endoscopy practices. Increasing use of gastrointestinal endoscopy has led to hospital budgets setting aside funds specifically related to damage to endoscopic instruments. Therefore, training in understanding endoscopic equipment, handling techniques, and equipment care can be helpful in addressing this issue. The aim of this study was to investigate the effects of educational courses and training about basic endoscopic handling and care in gastrointestinal endoscopic care and services.

Methods A number of new endoscopists, nurses, and nurse assistants were enrolled in a course for training in basic endoscopic handling and care. Data on the type of damage, cause, cost, and timing of endoscopic repair were prospectively collected. Data from the post-training period then were compared with retrospective data from the pretraining period.

Results This study demonstrated that after training, there was less damage to endoscopes, lower costs associated with it, and repair times were shorter for endoscopes than before the training course. Post-training results indicated savings of a total of $\$ 40,617.21$ or $£ 29,539.78$ and 102.6 days per damaged endoscope.

Conclusions Basic endoscopic handling and care training plays an important role for both endoscopists and nurses, as well as in endoscopy facilities, specifically in avoiding the nuisance of unwanted and broken endoscopes. This could be beneficial for both hospital finances and endoscopic services.

\section{Introduction}

Gastrointestinal diseases are a significant health problem worldwide and have a substantial impact on health care. Total expenditure for gastrointestinal diseases is \$135.9 billion annually, greater than for all other common diseases, and costs are likely to continue increasing [1].

The current dramatic revolution in the practice of endoscopists through emerging endoscopic technology and new techniques has played an important role in screening, diagno- sis, and treatment of many digestive diseases. An estimated 17.7 million endoscopic procedures are performed annually in the United States [1].

Today, endoscopic technology is developing continuously with various manufacturers offering complex components that affect the purchase price of endoscopes. In Thailand, an endoscope costs between $\$ 43,000$ and $\$ 84,000$, excluding the cost of the endoscopy video processor and light source. The increasing use of gastrointestinal endoscopy leads to hospital budgets being adjusted to allow for instrument damage and repair [2]. 
An endoscopy center is typically composed of healthcare providers, such as endoscopists and nurses, and an endoscopy suite. Education and training courses are important for maintaining the quality of endoscopic care and services [3-7] especially among new practitioners [8,9]. The reduction in damage to instruments also has a beneficial influence on endoscopic care due to less wasted time, economized costs, and the possibility that the quality of healthcare service could be improved $[10,11]$. Training in understanding the endoscopic equipment, plus care and handling techniques can be helpful in addressing these issues.

Currently, economic evaluations of health interventions are an interesting point for many studies and publications by integrating the quality of care with the education or created the statements or models [12-16]. Our hypothesis is that if the new endoscopists have a better understanding of the instruments and handling techniques that reduce preventable causes of damage plus the appropriate use of accessory instruments, and if the nurses and nurse assistants had knowledge of the anatomy of the endoscopic structures allowing them to prevent damage in technical endoscopic care, it will minimize unwanted costs and improve the quality of endoscopic patient care. The aim of this study was to investigate the effects of educational courses and training about basic endoscopic handling and care within gastrointestinal endoscopic care and services.

\section{Methods}

We enrolled six new endoscopists, 13 endoscopy nurses, and nine nurse assistants who worked in the Gastrointestinal Endoscopy Center, Thammasat University Hospital, Thailand, in a training course for basic endoscopic handling and care, held between October 7, 2017 and November 25, 2017. A new endoscopist was defined as being in his/her first year of training with experience of $<100$ endoscopic procedures. Lectures were given (45 minutes per topic) that addressed: (1) endoscopic components i.e. internal and external endoscope anatomy; (2) causes of damage by using, washing, storing the endoscope, and repair costs; (3) the appropriate use of accessory instruments like biopsy forceps, injection needle catheter, polypectomy snare, and causes of damage from accessory; (4) proper handling techniques and adequate endoscope care for durability; (5) hands-on practice using a porcine stomach model for beginner covering procedures like polypectomy, endoscopic mucosal resection, foreign body removal, glue injection and clipping, and controlling bleeding using a computer simulator; and (6) hands-on practical endoscopic care such as cleaning, disinfection, and storage following manufacturers' guidance for assembling and dismantling the endoscope and its accessory component and manual and machine disinfection and cleaning. Details of the training are given in the Supplementary Material. The pretest and post-test with lecture topics were created by the experience endoscopists and endoscopy nurses, developed from the retrospective data that were the causes and pitfalls of the broken endoscopes in the Gastrointestinal Endoscopy Center. The pretest and post-test constituted all topics of the lectures and hands-on in a training course. The participants were required to pass the test by scoring $\geq 80 \%$ and those who failed were required to repeat the training course and hands-on practice until they passed.

Data regarding the type, cause of damage, cost, and timing of endoscopic repair were collected prospectively (post-training) between December 2017 and November 2018 before being compared with the retrospective (pre-training) data collected between October 2016 and September 2017.

When a defect was detected in an endoscope, the endoscopy nurse and an engineer checked the instrument. The damages endoscope was sent for repair at a maintenance center outside the hospital and repair time was defined as the period until the endoscope was returned to the Gastrointestinal Endoscopy Center.

All data were analyzed using SPSS v.22.0 data (Statistical Package for Social Sciences, SPSS Inc., Chicago, Illinois, United States). The study was approved by the Human Ethics Committee of Thammasat University (Faculty of Medicine) with reference number; MTU-EC-SU-0-184/60.

\section{Results}

At the Gastrointestinal Endoscopy Center, Thammasat University Hospital, Thailand, we performed 2,573 gastroscopies and 1,950 colonoscopies over the 1 -year period from October 2016 to September 2017 and 2,716 gastroscopies and 2,277 colonoscopies from December 2017 to November 2018, using a total of 13 gastroscopes and seven colonoscopes. All of the endoscopes were new and had been used for $<1$ year. The procedures were performed by six new endoscopists and 17 boardcertified endoscopists from the Department of Surgery and Division of Gastroenterology, Department of Internal Medicine, along with 13 endoscopy nurses and nine nurse assistants.

The training took place between October 7, 2017 and November 25, 2017, during which no data were collected. Following our training course, the mean post-test scores overall and for each category significantly improved with a mean score of $96.88 \%$ and a pretest score of $69.87 \%$. In addition, all participants passed the post-test by scoring higher than $80 \%$; pretest and post-test scores are in the supplementary material.

The study revealed a total of 30 damaged endoscopes. It demonstrated the trend for less total damage ( $\triangleright$ Fig.1) and lower costs ( $\mathbf{F i g . 2}$ ) in post-training outcomes than the data collected before the training course. The results showed a significantly shorter duration required for repairing endoscopes after training than during the pre-training period ( $>$ Fig. $\mathbf{3}$ ).

The cost and repair time were different based on the type of endoscopes and the cause of damage. Post-training results saved a total of $\$ 40,617.21$ or $£ 29,539.78$ from the budget as well as 1,218 days required for repairing endoscopes. The average cost of repair was $\$ 5,421.09$ or $£ 3,942.61$ per damaged endoscope and the average duration of the repair process was 102.6 days per damaged endoscope. The main causes of damaged endoscopes were endoscope leak and nozzle and channel blockage ( $\triangleright$ Table 1$)$. (Estimated exchange rate average November 30, 2017: \$1 [United States] = Bt 32 (Thai) and $£ 1$ [UK] $=$ Bt 44 [Thai $]$. 

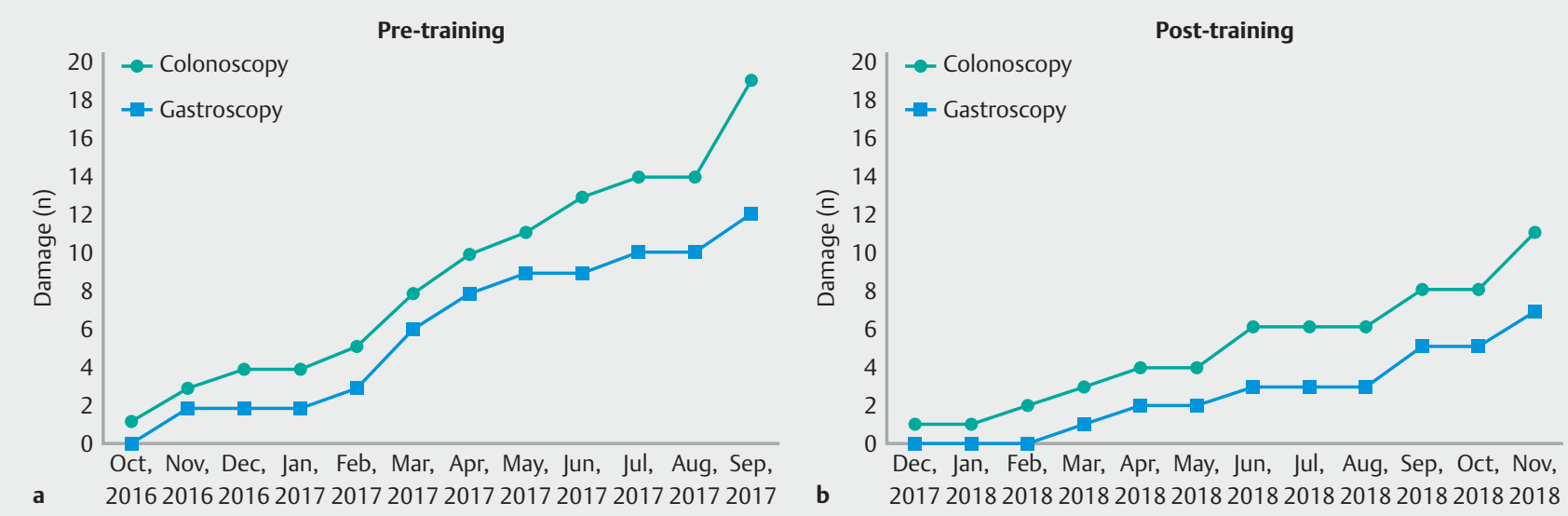

- Fig. 1 Cumulative amount of damage endoscope of pre- and post-basic endoscopic handling and care training. Cumulative total amount of damaged endoscopes collected retrospectively between a October 2016 and September 2017 compared with b prospective data collected between December 2017 and November 2018.

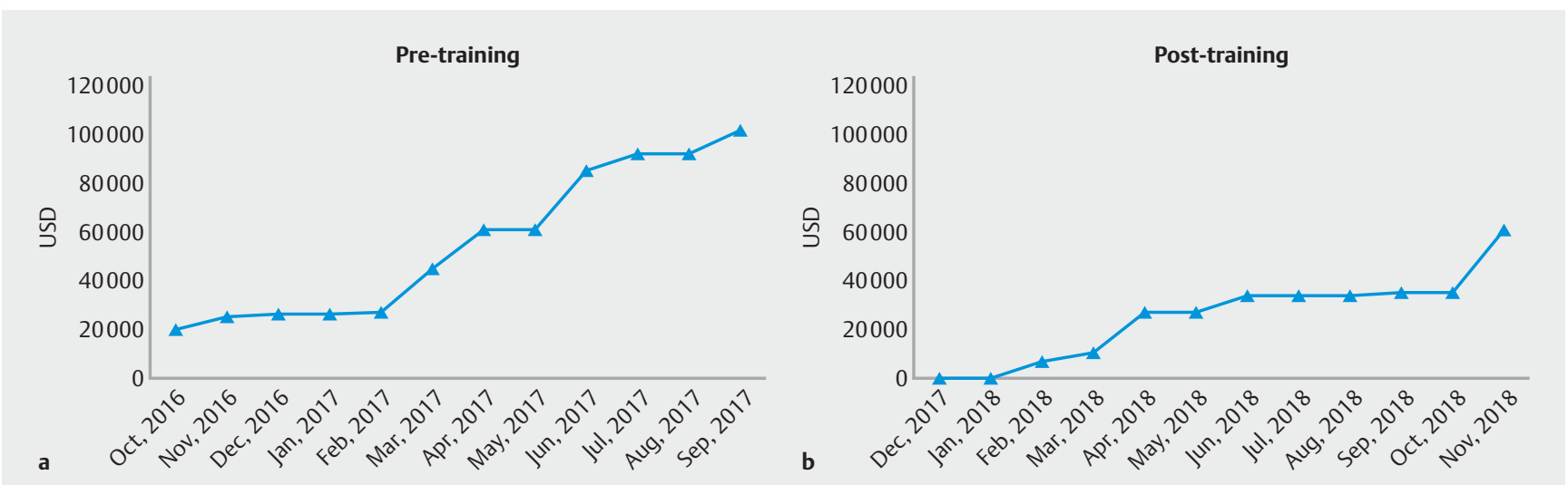

Fig. 2 Cumulative budget of pre- and post-basic endoscopic handling and care training periods. Cumulative total amount of repaired endoscopes during a the pre-training period demonstrated and compared with $\mathbf{b}$ the post-training period.

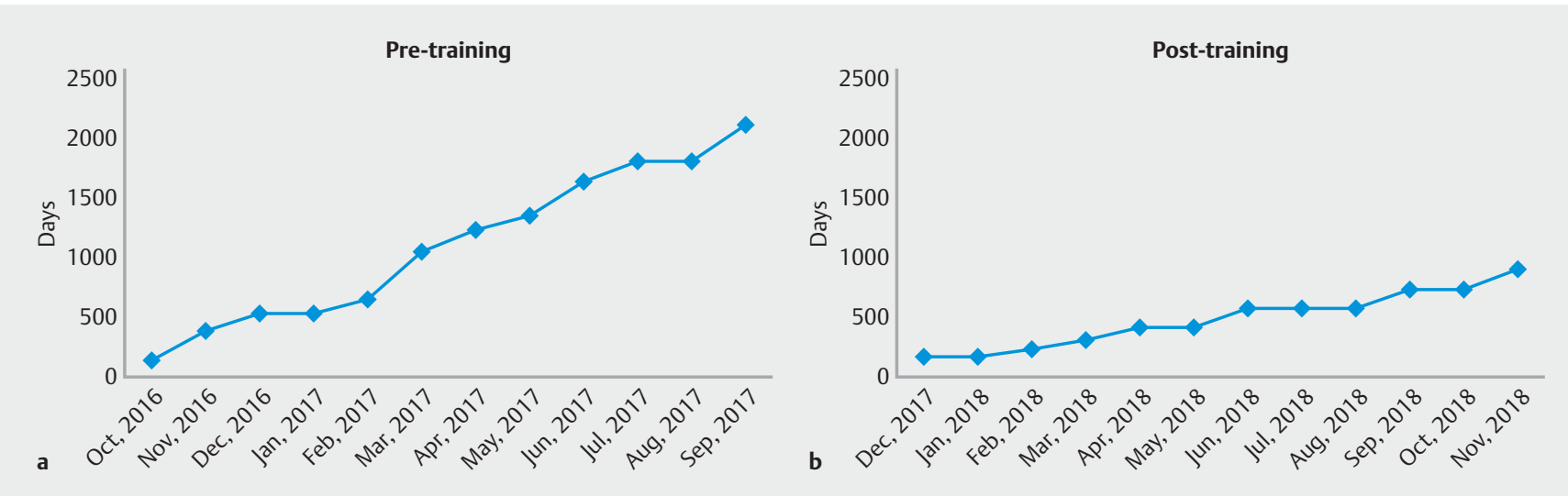

Fig. 3 Cumulative duration of repairing endoscopies for pre- and post-basic endoscopic handling and care training. Cumulative length of endoscopic repair was determined for a pre-training and $\mathbf{b}$ post-training courses. 
- Table 1 Details of endoscopic damage before and after basic endoscopic handling and care training.

\begin{tabular}{|c|c|c|c|c|}
\hline & $\begin{array}{l}\text { Pre-training (October 2016- } \\
\text { September 2017) }\end{array}$ & $\begin{array}{l}\text { Post-training (December 2017- } \\
\text { November 2018) }\end{array}$ & & \\
\hline & Damage (n) & Damage (n) & $P$ value & Total \\
\hline \multicolumn{5}{|l|}{ Type of endoscope } \\
\hline - Gastroscope & 12 & 7 & 0.283 & 19 \\
\hline - Colonoscope & 7 & 4 & 0.303 & 11 \\
\hline - Total & 19 & 11 & 0.145 & 30 \\
\hline \multicolumn{5}{|l|}{ Causes of problem } \\
\hline - Leak & 7 & 5 & 0.548 & 12 \\
\hline Cost & & & & Difference \\
\hline - THB & $2,595,416.64$ & $1,557,950$ & 0.481 & $1,037,466.64$ \\
\hline . USD & $81,106.77$ & $48,685.94$ & 0.481 & $32,420.83$ \\
\hline . GBP & $58,986.74$ & $35,407.95$ & 0.481 & $23,578.79$ \\
\hline - Nozzle and channel block & 9 & 2 & 0.045 & 11 \\
\hline Cost & & & & Difference \\
\hline . THB & $607,681.12$ & 320,620 & 0.449 & $287,061.12$ \\
\hline . USD & $18,990.03$ & $10,019.37$ & 0.449 & $8,970.66$ \\
\hline - GBP & $13,810.93$ & $7,286.82$ & 0.449 & $6,524.11$ \\
\hline - Control knob & 0 & 1 & 0.328 & 1 \\
\hline Cost & & & & Difference \\
\hline . THB & 0 & 1,500 & 0.323 & 1,500 \\
\hline - USD & 0 & 46.88 & 0.323 & 46.88 \\
\hline . GBP & 0 & 34.09 & 0.323 & 34.09 \\
\hline - Lens & 1 & 1 & 1 & 2 \\
\hline Cost & & & & Difference \\
\hline . THB & 1,500 & 24,260 & 0.355 & 22,760 \\
\hline . USD & 46.88 & 758.13 & 0.355 & 711.25 \\
\hline - GBP & 34.09 & 551.36 & 0.355 & 517.27 \\
\hline - Glue stick & 1 & 0 & 0.557 & 1 \\
\hline Cost & & & & Difference \\
\hline . ТHB & 20,300 & 0 & 0.322 & 20,300 \\
\hline . USD & 634.38 & 0 & 0.322 & 634.38 \\
\hline . GBP & 461.36 & 0 & 0.322 & 461.36 \\
\hline - Channel damage & 1 & 2 & 0.328 & 3 \\
\hline Cost & & & & Difference \\
\hline - THB & $27,102.8$ & 47,920 & 0.637 & $20,817.2$ \\
\hline - USD & 846.96 & $1,497.5$ & 0.637 & 650.54 \\
\hline - GBP & 615.97 & 1089.09 & 0.637 & 473.12 \\
\hline Repair budget & Total cost & Total cost & p value & Difference \\
\hline THB & $3,252,000.56$ & $1,952,250.00$ & 0.361 & $1,299,750.56$ \\
\hline USD & $101,625.02$ & $61,007.81$ & 0.361 & $40,617.21$ \\
\hline
\end{tabular}




\begin{tabular}{|c|c|c|c|c|}
\hline & $\begin{array}{l}\text { Pre-training (October 2016- } \\
\text { September 2017) }\end{array}$ & $\begin{array}{l}\text { Post-training (December 2017- } \\
\text { November 2018) }\end{array}$ & & \\
\hline & Damage (n) & Damage (n) & $P$ value & Total \\
\hline \multirow[t]{2}{*}{ GBP } & $73,909.10$ & $44,369.32$ & 0.361 & $29,539.78$ \\
\hline & Total time (day) & Total time (day) & $P$ value & Difference \\
\hline Endoscope repair duration & 2,123 & 905 & 0.007 & 1,218 \\
\hline \multicolumn{5}{|c|}{$\begin{array}{l}\text { Estimated exchange rate average as of November 30, 2017: } \\
\$ 1 \text { (United States) }=\mathrm{Bt} 32 \text { (Thai) } \\
\text { E1 (United Kingdom) = Bt } 44 \text { (Thai) }\end{array}$} \\
\hline
\end{tabular}

\section{Discussion}

With an increasing number of endoscopic procedures being performed, increased instrument damage has become a concern. Damaged endoscopes affect hospital finances [11] and opportunities for patients who need to undergo endoscopy.

At our Endoscopy Center, patient care is managed by a number of health care professionals. One important task in the mission of the university hospital is training of endoscopists and we add six new endoscopists every year. The endoscopic procedures that these doctors learn to perform present opportunities for instrument damage $[4,8,9]$. Other health care providers, nurses, and nurse assistants are also crucial in maintaining the quality of endoscopic care $[6,7]$. Together with patient care, nurses and nurse assistants play important roles in endoscopic care, particularly in terms of cleaning, disinfection, and storage. Previous studies have reported that improved education and training of personnel have resulted in a $35 \%$ reduction in instrument damage [10].

Our training course enrolled all new endoscopists, as well as all nurses and nurse assistants who work in our endoscopy center. The educational program was composed of sessions on personal awareness of endoscopy handling and manipulation, correct choice and accessory instrument usage, and strict adherence to cleaning, disinfection, carriage and storage, according to the recommendations of the endoscope manufacturer. An endoscopic hands-on workshop focused upon handling techniques for new endoscopists, focusing upon endoscopic technical care for nurses and nurse assistants.

Our institute performs approximately 2,500 gastroscopies and 2,000 colonoscopies per year, using 13 gastroscopes and seven colonoscopes. The present study found a decrease in the number of damaged endoscopes and resultant savings in the cost of repair. According to our analysis, post-training saved a mean of $\$ 5,421.09$ or $£ 3,942.61$ per damaged endoscope, translating to total repair budget savings of $\$ 40,617.21$ or $£ 29,539.78$ in 1 year. This is significant for our institution and could also be realized by other endoscopy units with limited budgets, especially given the current economic situation. The total cost of training courses for this study was estimated at $\$ 2,187.5$ or $€ 1,590$.9. Consideration of the multiple viewpoints by integrating the clinical practice with cost and value analysis is one of the concerning priorities for creating an evidence base towards education for the best benefit to the healthcare system [17-19].

Endoscope damage can be divided into preventable and non-preventable causes. Preventable damage can be prevented with proper care and handling techniques. On the other hand, non-preventable damage occurs due to deterioration over the lifetime of the endoscope. The results of this study showed all causes of damage. Nozzle and channel blockage was the most common cause of damage to endoscopes in the pre-training period. The reasons are due to not checking the endoscope before use, presence of tissue, foreign objects, or debris during service, not flushing the channels after use, and not cleaning the scope as soon as possible after the procedure. There was a particularly significant decrease in nozzle and channel blockage, which likely was due to improved care in endoscopic usage, cleaning, and technical care after a training course. However, the repair budget also was reduced after training, therefore, damage to the different types of endoscopes might have been affected by the cost of the repair. Also, differences in repair duration in the pre-training and post-training data may be one of the limitations of this study. This study was conducted in a single center with a small group of participants, over a short time, and with a limited number and type of endoscopic procedures. Further studies are required to evaluate and confirm the results of this study in multiple centers and more categories of endoscopy, such as endoscopic ultrasound (EUS), enteroscopy, and endoscopic cholangiopancreatography (ERCP).

Our study also showed the mean duration of repair was 102.6 days per damaged endoscope. The shorter duration of repairing endoscopes in the post-training period may be explained by the indirect effect of reducing the number of damaged endoscopes, which is the most likely cause of nozzle and channel block. However, when considering the cost of repairs at this point, it was found that the amount was reduced but not statistically different. In addition, this study did not analyze the degree of damage that might affect the duration and cost of repair. The conditional effect of minimizing the duration of endoscopic repair could be increased opportunities for endoscopic use for gastroenterology patients, and thereby, improvements in the quality of patient care. Although our education and training course revealed a decrease in total damage post-training, it is important to note that the rate of damage increased once again in the last month of the post-training peri- 
od, which might suggest forgetfulness or a relaxation in diligence. This should be investigated to inform post-training strategies to enhance skills retention over the long term [2022]. In this study, the post-course feedback was not analyzed; that might be another limitation. Better outcomes may have been achieved if the training intervention was reinforced with reminders while endoscopic procedures were being performed.

\section{Conclusions}

The financial impact of endoscopy services is increasing steadily due to more expensive accessories and procedures, which have widened the scope of practice. Training before handling costly and delicate instruments such as endoscopes is an a priori condition that should be the norm for every endoscopy practice. This study underscores the magnitude of potential savings, which is an interesting detail from a financial and cost-effectiveness point of view. Still, there is little added value from a scientific vantage point. Training for doctors and nurses handling endoscopic equipment is mandatory and beneficial from medical and financial points of view.

We therefore recommend refresher training courses and support for educational programs and workshops for health care providers in the Gastrointestinal Endoscopy Center. Basic endoscopic handling and care training plays an important role for endoscopists, nurses, and endoscopy facilities in avoiding unwanted and broken endoscopes, which can benefit both hospital finances and endoscopy services.

\section{Acknowledgements}

This work was supported by Research Group in Surgery, Faculty of Medicine, Thammasat University. Special thanks to Associate Professor Michael Guest and Dr. Bob Tayler for assistance in editing the English version of this paper and to Thanomphong Teerakulphisut and Chatchanok Lupakchee for their assistance in data collection for this manuscript.

\section{Competing interests}

The authors declare that they have no conflict of interest.

\section{References}

[1] Peery AF, Crockett SD, Murphy CC et al. Burden and cost of gastrointestinal, liver, and pancreatic diseases in the United States: update 2018. Gastroenterology 2019; 156: 254-272

[2] Loras C, Mayor V, Fernández-Bañares F et al. Study of the standard direct costs of various techniques of advanced endoscopy. Comparison with surgical alternatives. Dig Liver Dis 2018; 50: 689-697

[3] Biswas S, Alrubaiy L, China L et al. Trends in UK endoscopy training in the BSG trainees' national survey and strategic planning for the future. Frontline Gastroenterol 2018; 9: 200-207
[4] Ekkelenkamp VE, Koch AD, de Man RA et al. Training and competence assessment in GI endoscopy: a systematic review. Gut 2016; 65: 607615

[5] Patel SG, Keswani R, Elta G et al. Status of competency-based medical education in endoscopy training: a nationwide survey of US ACGMEaccredited gastroenterology training programs. Am J Gastroenterol 2015; 110: 956-962

[6] Verschuur EM, Kuipers EJ, Siersema PD. Nurses working in GI and endoscopic practice: a review. Gastrointest Endosc 2007; 65: 469479

[7] Yu S, Roh YS. Needs assessment survey for simulation-based training for gastrointestinal endoscopy nurses. Nurs Health Sci 2018; 20: 247254

[8] Lee SH, Park YK, Lee DJ et al. Colonoscopy procedural skills and training for new beginners. World J Gastroenterol 2014; 20: 16984-16995

[9] Lee SH, Park YK, Cho SM et al. Technical skills and training of upper gastrointestinal endoscopy for new beginners. World J Gastroenterol 2015; 21: 759-785

[10] Skogås JG, Mårvik R. Measures taken to reduce damage and repair costs of rigid endoscopes during their handling and processing in surgical practice. Minim Invasive Ther Allied Technol 2003; 12: 76-81

[11] Kramolowsky E, McDowell Z, Moore B et al. Cost analysis of flexible ureteroscope repairs: evaluation of 655 procedures in a communitybased practice. J Endourol 2016; 30: 254-256

[12] Husereau D, Drummond M, Petrou S et al. Consolidated Health Economic Evaluation Reporting Standards (CHEERS) statement. Cost Eff Resour Alloc 2013; 11: 6

[13] Zendejas B, Wang AT, Brydges R et al. Cost: the missing outcome in simulation-based medical education research: a systematic review. Surgery 2013; 153: 160-176

[14] Maloney S, Cook DA, Golub R et al. AMEE Guide No. 123 - How to read studies of educational costs. Med Teach 2019; 41: 497-504

[15] Tolsgaard MG, Tabor A, Madsen ME et al. Linking quality of care and training costs: cost-effectiveness in health professions education. Med Educ 2015; 49: 1263-1271

[16] Cook DA, Andersen DK, Combes JR et al. The value proposition of simulation-based education. Surgery 2018; 163: 944-949

[17] Maloney S, Reeves S, Rivers G et al. The Prato Statement on cost and value in professional and interprofessional education. J Interprof Care 2017; 31: 1-4

[18] Walsh K, Levin H, Jaye $P$ et al. Cost analyses approaches in medical education: there are no simple solutions. Med Educ 2013; 47: 962 968

[19] Foo ], Ilic D, Rivers G et al. Using cost-analyses to inform health professions education - The economic cost of pre-clinical failure. Med Teach 2018; 40: 1221-1230

[20] Kruidering-Hall M, O'Sullivan PS, Chou CL. Teaching feedback to firstyear medical students: long-term skill retention and accuracy of student self-assessment. J Gen Intern Med 2009; 24: 721-726

[21] Offiah G, Ekpotu LP, Murphy S et al. Evaluation of medical student retention of clinical skills following simulation training. BMC Med Educ 2019; 19: 263

[22] Ericsson KA. Deliberate practice and the acquisition and maintenance of expert performance in medicine and related domains. Acad Med 2004; 79: S70-S81 